The Effectiveness of Concept Maps for Students' Learning and Retention

\author{
Brady Collins \\ Robert Nyenhuis \\ Department of Political Science, Cal Poly Pomona, Pomona, USA \\ 3801 West Temple Avenue \\ Building 94, Room 303 \\ Pomona, CA 91768-4055 \\ Emails: \\ bjcollins@cpp.edu \\ renyenhuis@,cpp.edu
}




\title{
The Effectiveness of Concept Maps for Students' Learning and Retention
}

\author{
Abstract \\ The active learning literature has greatly expanded over the past few years. This article investigates the \\ utility of employing concept map activities in a medium-sized class, and whether or not it improves \\ students' learning and retention of material. We find that concept mapping activities significantly enhance \\ students' mastery and recollection of class material. The size of the effect is considerably greater in our \\ treatment group, relative to our control group. We discuss the advantages of this specific active learning \\ technique, and offer suggestions for its incorporation into different institutional settings.
}

Keywords: active learning, concept maps, pedagogy, teaching

Word Count [5423 words, including endnotes, additional disclaimers and references]

\section{Introduction}

Upon starting their academic careers, new faculty often experience the dual burden of needing to develop teaching materials for new classes they are assigned to, while also feeling pressure to demonstrate their expertise to students and peers by covering a wide breadth and depth of content. In this context the traditional lecture format is attractive both for its familiarity and simplicity. And, faced with growing class sizes or heavier course loads at teaching-oriented institutions, these pressures are amplified. Unfortunately, this pattern prevails simultaneously to the ever-expanding body of research that shows modifying the traditional lecture yields positive results in terms of student learning.

Studies on active learning — or the use of classroom strategies that ask students to engage with one another in higher-order thinking — have generated a plethora of tools and activities available to faculty who wish to moderately or significantly adjust their pedagogical style. In fact, the sheer number of different techniques can be overwhelming (Faust and Paulson 1998). Nevertheless, numerous obstacles exist to successfully integrating active learning into one's curriculum (Bonwell and Eison 1991): namely the potential increase in preparation time, a lack 
of materials or resources, and fear of criticism or failure. To address this, instructors invested in active learning need both support from their peers and research that highlights the effectiveness of specific learning techniques.

The purpose of this article is to test the effectiveness of one specific active learning technique with few barriers to entry: concept mapping. A concept map is a visual representation of information that depicts the hierarchical and relational organization of different concepts and theories. Consisting of mainly bubbles, lines, arrows, and text, concept maps ask students to map out material in a way that makes intuitive sense to them. If done iteratively, it also allows them to reorganize their maps as they are exposed to more and more information. Using quasiexperimental design, the authors of this paper address the following question: what impact does concept mapping have on students' knowledge acquisition and learning retention?

This paper unfolds as follows: the next section covers early and recent literature on active learning techniques with a focus on its use in political science classrooms. This is followed by a brief discussion of the active learning strategies program developed by the Association for College and University Educators (ACUE), of which the two authors of this study were active participants. ${ }^{1}$ The subsequent section explains the findings of the study and its implications. In short: we find that concept mapping has a positive and significant impact on student learning and retention. The article concludes with suggestions for future research.

\section{Literature Review}

Since the 1980s, college faculty have shown an interest in non-traditional pedagogical techniques and strategies as an alternative to the typical uninterrupted lecture format of the

\footnotetext{
${ }^{1}$ While ACUE was not a fiscal sponsor of this research, the ACUE course supported the authors in their research endeavours by providing them with online resources and peer support.
} 
university classroom. Early pioneers referred to such approaches as "active learning" (Bonwell and Eison 1991; Meyers and Jones 1993; Silberman 1996) in that they involve a variety of instructional activities that ask students to do things and actively think about what they are doing. Since then, "active learning" has become a buzzword in academia—research abounds as to the variety of positive impacts of active learning strategies. Scholars argue that active learning strategies help students learn significantly more information (Deslauriers 2011; Hake 1998; Knight and Wood 2005; Ruhl et al 1987;), develop students' critical thinking skills (McKeachie et al 1986; Waitkus 2011), and improve student in-class participation and risk-taking (Lowman 1984; Sidelinger 2010). Since this work first emerged, active learning has become particularly prominent among science educators, as many believe it allows students to connect dense content from readings and lecture to their real-world applications (National Research Council 1997, 2003; National Science Foundation 1996). With that said, it has also gained prominence in political science education (Archer and Miller 2011; Burch 2000; Jones \& Bursens 2015; Lantis et al 2000; Loggins 2009).

The term active learning can be further broken down into subcategories of teaching techniques. Davidson and Major (2014) describe three separate approaches: 1) cooperative learning; 2) collaborative learning; and 3) problem-based learning (PBL). According to them, while each of these categories share some common elements and can be defined in a variety of ways, they also have key differences. Cooperative learning places students in groups as they complete a variety of tasks, and lead their own inquiry and discussion, and help one another learn the material. The instructor's job is to assign roles and manage the reflection and questioning process. While also relying on group activities, collaborative learning differs in that the instructor takes a much more hands-off approach, whereby student roles are not assigned and the 
instructor is seen as another collaborator in the process of knowledge acquisition and application (Davidson and Major 2014). Lastly, in PBL, student groups are often working with a "client" in either a real-time or a simulated format (i.e. role playing) that allows them to apply their skills to real-world issues.

Despite this added nuance, some have argued that active learning continues to be rather broadly employed and studied, when in fact it more aptly describes a general approach to teaching that can be comprised of a variety of specific teaching methods. To this end, scholars have honed in on numerous techniques and activities that constitute active learning. Some of these include actual tasks that students complete, such as the "one-minute paper" (Angelo and Cross 1993) or the creation of concept maps (Novak 1990; Novak and Gowin 1984). Others emphasize techniques that can be adopted by the instructor themselves, such as adding wait time after questions (Rowe 1980; Schaible and Rhodes 1992) or using "finger signals" to test student comprehension (Meltzer and Manicannan 1996). Ruhl et al (1987) argue that the very structure of the class itself must be scrutinized. Given the relatively short attention span of the average student (Wankat 2002), they argue that class sessions should be broken up every 10-15 minutes with some kind of active learning technique in order to allow students the opportunity to absorb the material, and instructors the opportunity to become aware of information gaps.

In attempting to measure the impacts of active learning techniques such as these, the literature varies widely on the design and methods of gathering and testing empirical data. And, as mentioned, scholars have focused on different impacts of active learning, from exam scores to student participation. While a meta-analysis of studies on active learning suggests that, in general, students will remember more content if brief activities are introduced to the lecture, Prince (2004) points out a number of methodological and internal validity issues that permeate 
many studies on active learning. For example, given the broad definition of active learning, many studies attempt to measure the impacts of numerous pedagogical techniques at once, thereby muddying their ability to determine whether particular instructional methods are more effective than others. Others incorrectly point to moderate improvements in exam scores as evidence that a learning technique definitively worked (Colliver 2000), when in fact there are a variety of factors that can influence exam scores. This problem is confounded by the fact that measuring what we actually care about as educators--e.g. classroom participation, lifelong learning, study habits--is very difficult to do (Prince 2004). As a result, many studies rely on self-reporting from students, which may be useful in measuring student perceptions (Sidelinger 2010), but is inappropriate for testing knowledge retention or behavioral change. Instead, preand post-test studies that measure learning retention are oft-cited as the most reliable tests of the effectiveness of active learning (Chin et al 2009; Elias 2013; Gosen and Washbush 2004).

Within political science education specifically, active learning is praised not only for its positive impact on student learning but also its ability to spark students' interest in the discipline and politics in general (Burch 2000; Dougherty 2003; Lantis et al 2000; Loggins 2009; Shellman and Turan 2006). As the social science and humanities face increased pressure to cultivate professional skills among students, active learning within political science allows educators to provide students with practical, hard skills that are transferable to their career interests. This includes public speaking, negotiation, and drafting and presenting reports (Jones and Bursens 2015). However, the literature on active learning in political science focuses overwhelmingly on in-class simulations, whereas other methods like team-based learning and PBL receive much less attention (Ishiyama 2012). Moreover, the "gateway classes" in which these strategies are employed are typically Intro to American Government, Intro to Comparative Politics, Intro to 
International Relations, and Intro to Political Theory, with Intro to Public Administration courses largely overlooked (Archer and Miller 2011). By examining a team-based active learning strategy in the context of a public administration course, this article seeks to fill this gap.

This research also seeks to inform "educating the educator" programs aimed at encouraging new faculty to use active learning strategies. Despite the evidence that active learning works, there are several key barriers to its successful integration into the classroom. Some faculty report that their attempts to incorporate active learning into their curriculum was met with student anxiety, anger, and even resistance (Felder and Brent 1996). As a result, despite the possibility that such strategies might lead to grade improvements, the potential for poor student evaluations may defer some, and particularly junior, faculty. Others point to very practical challenges, such as the misaligned incentives facing faculty. For example, faced with the possibility of an increase in class preparation time and little to no reward for their efforts from tenure and promotion committees, it is understandably difficult to inspire faculty to change teaching styles (Bonwell and Eison 1991). Nevertheless, given the evidence supporting active learning, as well as the growing rhetorical emphasis on skills-building as a means for preparing young people for the workforce, some posit that this growing trend may ultimately "overthrow" the lecture (Lambert 2012).

In this context, the Association for College and University Educators (ACUE) has designed an online course that both educates faculty on active learning techniques while also creating a community of faculty dedicated to testing them out in their respective classes and sharing challenges and best practices. As described on their website, ACUE prepares faculty to use "evidence-based teaching practices that promote student engagement, persistence to graduation, career readiness, and deeper levels of learning" (ACUE 2019). The online course for 
faculty is comprised of a series of modules that walk users through a wide variety of pedagogical strategies, from assessment tools to facilitating group activities. These modules involve a series of videos-including "mock" classrooms where viewers see instructors successfully and unsuccessfully employing different techniques - quizzes, and discussion forums. The purpose of the course is to not only expose faculty to active learning strategies; it also asks that they develop plans for implementation that lay out how these strategies will be incorporated into their class plans and syllabi. ACUE also works towards building teacher efficacy (Chase et al 2001), in that it encourages faculty to establish a more reflective teaching practice. The authors of this article both participated in ACUE's year-long course. As such, this study aims to not only evaluate the effectiveness of active learning methods in the classroom but also to help inform the ACUE model.

\section{Research Design and Methods}

The purpose of this study was to test the effectiveness of a particular active learning method on student learning and knowledge retention. It was carried out in the second semester of the 2018-19 academic year at California State Polytechnic University, Pomona, during which one of the researchers taught two sections of the same introductory political science course, "Introduction to Public Administration". This lower-division course covers a broad range of standard topics in public administration, from policy making and regulation to human resource and financial management. One section served as the control group and the other as the treatment group. Enrollment in each section was about the same (45 and 46 students, respectively). The instructor, who had previously taught this course for two years, designed the course so that there 
are three exams covering three separate sections of course material (i.e. the exams are not cumulative in terms of content). Each section is approximately five weeks long.

Having started the ACUE course at the beginning of the semester, the researchers used the second section of the course as the intervention. During this portion of the class, the instructor employed an active learning technique for which he received training in the ACUE modules: concept mapping. An example of a concept map developed in the treatment class with students is shown below.

[Figure 1 here]

In this particular concept map, students were asked to show visually the constitutive elements of two opposing theoretical approaches to public administration: classical theory and "new public management". By mapping out the two theories, students are able to more easily see how one theory builds off and critiques the other. One active learning method was employed rather than a selection of several in order to avoid the conceptual obscurity of previous active learning studies (Deslauriers et al 2011). Furthermore, as mentioned, concept mapping is significantly understudied within political science education with in-class simulations (such as EUSim or Model UN) dominating the literature on active learning (Cliotta-Rubery and Levy 2000; Ishiyama 2012). The purpose of a concept map is to have students establish a hierarchical and relational organization of their understanding of a certain subject of concept. Concept maps are particularly useful if they are done iteratively, in that they force students to organize and reorganize their knowledge as they are exposed to more and more information (Ortega and Brame 2015). As shown above, during a day focused on organizational theory, students would 
create a concept map that depicts visually how different studies, concepts, and/or theories relate to one another. During the second section of the course, the instructor led groups of students in the treatment group through concept mapping exercises. These exercises were done on the majority of regular class days and were conducted either in small groups independently by students or together as a class on the white board. Concept mapping was also used during the full day of exam review.

In order to test the effectiveness of this active learning method the instructor distributed the same anonymous survey to both control and treatment groups at three points during the semester: once during week 6, right before the second section of the course began (i.e. "pre-test", before the intervention), once during week 10 at the end of the second section (i.e. "post-test 1", right after the intervention), and finally during week 15 at the end of the semester (i.e. "post-test 2", after the third section had concluded). Students were given an ID number so that we could track their performance on the survey anonymously over time. It is worth noting that during the third section of the course the concept mapping exercise was no longer used. This allowed us to identify precisely whether concept mapping improved student learning and retention of the material covered during the second section of the course.

Incorporating the concept mapping exercises into the classroom required restructuring each session. For the treatment group, the classes were typically structured in the following way: administrative issues/updates (5 minutes); lecture (12-15 minutes); initial concept mapping exercise (8-10 minutes); lecture (12-15 minutes); second concept mapping exercise, adding and synthesizing information (15-20 minutes); group quiz or activity (12-15 minutes). The final group quiz or activity section of the class is a regular part of the instructor's teaching, and thus was constant in both class sections. Therefore, for the control group as well as the two sections in 
the experimental group during which there was no intervention, the classes were typically structured as follows: administrative issues/updates (5 minutes); lecture (35-50 minutes); group quiz or activity (12-15 minutes).

Despite the merits of the quasi-experimental design employed in this study, there are a couple important limitations to acknowledge. Attrition posed challenges throughout the study as many students did not attend class on the days during which the knowledge retention surveys were distributed. Due to variation in class attendance, our final sample included only students who both attended all class sessions and participated in all surveys. We acknowledge that this may bias the sample by including only the most motivated and likely best-performing students. However, one could also imagine these students as having the highest starting points (best scores) and having less room from improvement. We feel that these effects likely wash out over the course of a semester and given that our samples are relatively large for a classroom setting $(\mathrm{N}=26)$. Further, we chose to conduct our analysis at the class level and use a difference of means tests between the two groups. The advantage of this approach is that we did not have to control for individual level characteristics for which we do not have the appropriate data, such as year in college or major. Moreover, because of privacy concerns, we relied on ID numbers for the survey and therefore are unable to match students' performance on exams to their scores on the surveys. We can therefore only test averages for both treatment and control groups. Lastly, given the interactional component of the active learning lessons the instructor utilized, we feel that the learning techniques may produce overall benefits not only at the individual but group level. Nevertheless, we believe the findings of this study make important contributions to our understanding of the effectiveness of active learning methods on knowledge transfer and retention in political science education. 


\section{Findings and Analysis}

Table 1 illustrates the results of a series of difference of means tests for the two groups, control and treatment, on their material retention between the pre-and post- 1 surveys, and the post- 1 and post- 2 surveys. Vital for our study's research design, the initial knowledge bases for the two different classes were quite similar. The two groups were also comparable in terms of the students' year in program and major of the student. The control group had three non-majors and the treatment group had seven. As shown below in Figures 2 and 3, they only differed slightly in terms of the number of sophomore and juniors, with the control group having a slightly higher proportion of juniors. In addition, both classes had a median score of 92 on their first exam.

[Figure 2 here]

[Figure 3 here]

In terms of the surveys, the control group has a slightly lower starting point (class average of 2.92) compared to the treatment group (class average 3.00). The control group class saw a desired increase of 1.35 in the class average between the two time points, and the difference in class means was statistically significant at the 0.001 level. The class average did, however, decrease from 4.27 to 3.92 from the post- 1 to post- 2 surveys, as we expected. The decline in material retention was not a statistically significant one, as $p>0.349$, indicating that students retained quite a bit of material from the second section that they remembered five weeks later while absorbing and being tested on new information. 
The improvement and subsequent retention levels were much higher in the treatment groups. Starting from a similar position, the treatment group class average increased 2.35, a full point higher than the control group, suggesting that techniques employed in their class discussions enabled them to more easily pick up the course material. The marked mean difference is also statistically significant at the $\mathrm{P}<0.001$ level. When examining the treatment group's retention, again the evidence illustrates that the active learning instruction accomplished what we had hoped for-students retained information they learned the previous month to a remarkable degree. Although the class mean decreased by 0.12 , it was about one-third of the drop sustained by the control group; and the change is much further away from approaching statistical significance. In short, students in the treatment group grasped material much quicker and retained the information better than their academic peers.

\section{[Table 1 here]}

Our results are displayed below in figure 4 and figure 5, providing a visual illustration of the results. One nice feature is that the box plots include a distribution of the scores. The graphics demonstrate additional findings. Beyond improving class averages, the treatment group's scores distribution at the third time point (figure 5, picture on the right) indicate that fewer students scored as poorly as they did at time point two, suggesting that the positive learning effects filtered down even to the worst performing (measured by the surveys) students. In other words, the metaphorical "floor" of student performance was raised in the treatment group. Conversely, the "ceiling" lowered among the highest scoring students in the control group. The picture on the 
right in figure 4 illustrates that although the class averages decrease marginally across the two time points, the scores of the top performers are in fact lower.

[Figure 4 here]

[Figure 5 here]

\section{Discussion}

Our results lead us to draw two preliminary conclusions. First, there is value to both styles of teaching, and each can yield normatively beneficial results for student learning. Second, although both styles deliver statistically significant results, the treatment class who were exposed to active learning techniques performed considerably better in improvement and retention.

The control group class structure provided greater time for traditional structured lecture but also incorporated a group quiz (or activity) at the end. Some students may prefer the more conventional instructional technique and shy away from alternative approaches. Our results provide evidence that students do learn and retain information in majority-lecture settings. It is worth noting that the group quiz or activity that were held at the end of class in both the treatment and control groups also constitute active learning techniques. As such, we cannot in confidence claim that lecture-heavy classes improved scores as a result of the lecture emphasis, but rather likely resulted from a mix of lecture and moderate use of active learning techniques.

Our second conclusion implies that greater benefits can be obtained if classes are structured to blend both lecture and active learning exercises, in this case concept mapping activities. Below we discuss the specific mechanism we believe aided in students' learning and 
retention. Concept maps, and their implementation, are designed to encourage students to revisit their foundations of knowledge, carefully refining their contents as they are exposed to new, and possibly conflicting, information. This iterative learning process develops students analytical wherewithal as they constantly must assess and then reassess how new information fits in with their existing cognitive/knowledge paradigm/template. In this specific class, the instructor utilized concept maps to construct a constantly evolving knowledge base or inventory, of sorts. The instructor emphasized how material from the previous week connected to the material students were learning in the current week. This style of teaching may have implicitly, even explicitly, provided cognitive cues to students of what material may have been important. Drawing connections across weeks through the use of concept maps and having students actively participate in constructing these diagrams placed the agency squarely on the students, ensuring that they had to consistently engage with course material. Rather than simply stating or alluding to the importance of material as is often done in traditional lecture, in these active learning exercises the intellectual onus fell on students to identify key material. Acting almost as pedagogical stakeholders, students developed analytical frameworks that helped them absorb new material and their memories were frequently activated and tested; both sets of skills aiding their informational absorption and retention.

\section{Conclusion}

This research indicates that use of active learning techniques - and specifically concept mapping - can improve student learning and knowledge retention in political science courses. These findings are important for several reasons. First, previous research on active learning in political science courses has overwhelmingly focused on in-class simulations such as mock trials 
and Model UN exercises, with little regard for other active learning techniques. By investigating the effectiveness of concept mapping within an intro-level public administration class, this paper paves new ground for instructors in public policy, administration, and management who wish to experiment with active learning strategies, but may have little experience with developing indepth simulations and which arguably require more out-of-class preparation.

Second, whereas previous studies have bundled active learning techniques together in order to investigate learning outcomes, the design of this study allows us to identify the impacts of one specific active learning technique. Our findings suggest that the introduction of concept mapping into course curricula has the potential to significantly impact student learning, and therefore may be a useful starting point for instructors who wish to use active learning strategies but are unsure of which technique to begin with, and are looking for an option with low barriers to entry but high potential for results.

Lastly, our study lends support to programs like ACUE that train cohorts of instructors on active learning strategies and provide real-time coaching on implementation. In fact, it is possible that the instructors in this study experienced greater results not simply because of their integration of active learning techniques, but also because of their participation in the ACUE program that provided them with additional resources and support as they explored new ground in their teaching. College deans or Department heads wishing to expand the use of active learning among their faculty might consider partnering with ACUE or similar institutions that offer online trainings for instructors.

Our study does have some potential limitations. The highest class average on the learning retention quiz was approximately $69 \%$. The quiz had only eight multiple choice questions, suggesting that the survey was quite difficult for students. At the same time, it may also indicate 
that active-learning yields great benefits even when the material is complex and the assessments challenging. However, we encourage future researchers to consider testing learning retention with other types of assessments, such as open-ended writing questions or interviews. A more qualitative approach may yield more nuanced results in terms of what kinds of information students are retaining versus others. Nevertheless, we are confident that our study lends strong support to active learning strategies, and specifically to courses such as ACUE that support faculty as they explore uncharted territory in their teaching.

\section{Acknowledgements}

The authors thank the Association of College and University Educators (ACUE) for the helpful active learning strategies and accompanying tutorials.

\section{Disclosure Statement}

No potential conflict of interest was reported by the author.

\section{ORCID}

Brady Collins, https://orcid.org/0000-0001-9377-3093

Robert Nyenhuis, https://orcid.org/0000-0003-4742-5594

\section{References}

Angelo, T.A. \& Cross, K.P. (1993). Classroom assessment techniques. San Francisco: JosseyBass.

Archer, C. C., \& Miller, M. K. (2011). Prioritizing Active Learning: An Exploration of Gateway Courses in Political Science. PS: Political Science \& Politics, 44(02), 429-434. https://doi.org/10.1017/S1049096511000291

Bonwell, C. \& Eison, J. (1991). Active Learning Creating Excitement. ERIC Clearing House on Higher Education, Washington DC: George Washington University. https://files.eric.ed.gov/fulltext/ED340272.pdf 
Burch, K. (2000). A Primer on Problem-Based Learning for International Relations Courses. International Studies Perspectives, 1, 33-44.

Chase, B, Germundsen, R., Brownstein, J.C., \& Distad, L.S. (2001). Making the Connection between Increased Student Learning and Reflective Practice. Educational Horizons, 79(3), 143-147

Chin, J., Dukes, R., \& Gamson, W. (2009). Assessment in simulation and gaming. A review of the last 40 years. Simulation and Gaming, 40(4), 239-244.

Ciliotta-Rubery, A., \& Levy, D. (2000). Congressional Committee Simulation: An Active Learning Experiment. 6.

Colliver, J. (2000). Effectiveness of Problem-Based Learning Curricula. Academic Medicine, 75, 259.

Davidson, N. \& Major, Claire H. (2014). Boundary Crossings: Cooperative Learning, Collaborative Learning, and Problem-Based Learning. Journal on Excellence in College Teaching, 25(3\&4), 7-55.

Deslauriers, L., Schelew, E., \& Wieman, C. (2011). Improved Learning in a Large-Enrollment Physics Class. Science, 332(6031), 862-864. https://doi.org/10.1126/science.1201783

Dougherty, B. (2003). Byzantine Politics: Using Simulations to Make Sense of the Middle East. PS: Political Science \& Politics, 36, 239-244.

Elias, A. (2013). Simulating the European Union: Reflections on module design. International Studies Perspectives, 15(4), 407-422

Felder, R.M., and Brent, R. (1996). Navigating the bumpy road to student-centered instruction. College Teaching 44(2), 43-47.

Gosen, J. \& Washbush, J. (2004). A review of scholarship on assessing experiential learning effectiveness. Simulation and Gaming, 35(2), 270-293.

Hake, R. R. (1998). Interactive-engagement vs traditional methods: A six- thousand- student survey of mechanics test data for introductory physics courses. American Journal of Physics 143, 1-26.

Ishiyama, J. (2013). Frequently used Active Learning Techniques and Their Impact: a Critical Review of Existing Journal Literature in the United States. European Political Science, 12(1), 116-126. https://doi.org/10.1057/eps.2012.3

Jones, R., \& Bursens, P. (2015). The effects of active learning environments: how simulations trigger affective learning. European Political Science, 14(3), 254-265. 
https://doi.org/10.1057/eps.2015.22

Knight, J. K., \& Wood, W. B. (2005). Teaching More by Lecturing Less. Cell Biology

Education, 4(4), 298-310. https://doi.org/10.1187/05-06-0082

Lantis, J., Kuzma, L.M., \& Boehrer, J. (2000). The New International Studies Classroom: Active Teaching, Active Learning. New York: Lynne Rienner.

Lambert, C. (2012). Twilight of the Lecture. Harvard Magazine. https://harvardmagazine.com/2012/03/twilight-of-the-lecture

Loggins, J. (2009). Simulating the Foreign Policy Decision-Making Process in the Undergraduate Classroom. PS: Political Science \& Politics, 42, 175-179

Lowman, J. (1984). Mastering the Techniques of Teaching. San Francisco: Jossey-Bass.

McKeachie, W. (1972). Research on College Teaching. Educational Perspectives, 11(2), 3-10

Meltzer, D.E. \& Manicannan, K. (1996). Promoting interactivity in physics lecture classes. The Physics Teacher, 34, 72-76.

Meyers, C. \& Jones, T. (1993). Promoting active learning: Strategies for the college classroom. San Francisco: Jossey-Bass.

National Research Council, Committee on Undergraduate Science Education (1997). Science Teaching Reconsidered: A Handbook. Washington, DC: National Academies Press.

National Research Council, Committee on Undergraduate Science Education (2003). Improving undergraduate instruction in science, technology, engineering and mathematics: Report of a workshop. Washington, DC: National Academies Press.

National Science Foundation (1996). Shaping the Future: New Experiences for Undergraduate Education in Science, Mathematics, Engineering and Technology. Report of the Advisory Committee to the NSF Directorate for Education and Human Resources. Washington, DC.

Novak, J.D. (1990). Concept mapping: A useful tool for science education. Journal of Research in Science Teaching, 27, 937-949

Novak, J.D. \& Gowin, D.B. (1984). Learning how to learn. New York: Cambridge University Press.

Ortega, R. A., \& Brame, C. J. (2015). The Synthesis Map Is a Multidimensional Educational Tool That Provides Insight into Students' Mental Models and Promotes Students' Synthetic Knowledge Generation. CBE-Life Sciences Education, 14(2), ar14. https://doi.org/10.1187/cbe.14-07-0114 
Prince, M. (2004). Does Active Learning Work? A Review of the Research. Journal of Engineering Education, 93(3), 223-231. https://doi.org/10.1002/j.21689830.2004.tb00809.x

Rowe, M.B. (1980). Pausing principles and their effect upon reasoning in science. In F.B. Brawer (Ed.), Teaching the sciences (p 27-34). New Directions in Community Colleges, No. 31. San Francisco: Jossey-Bass.

Ruhl, K. L., Hughes, C. A., \& Schloss, P. J. (1987). Using the Pause Procedure to Enhance Lecture Recall. Teaching Education and Special Education, 10(1), 14-18

Schaible, R. \& Rhodes, G. (1992). Metaphor in science and literature: Creating an environment for active interdisciplinary learning. Journal of College Science Teaching, 12, 100.

Shellman, S.M. \& Turan, K. (2006). Do Simulations Enhance Student Learning? An empirical Evaluation of an IR Simulation. Journal of POlitical Science Education, 2, 19-32.

Sidelinger, R. J. (2010). College Student Involvement: An Examination of Student Characteristics and Perceived Instructor Communication Behaviors in the Classroom. Communication Studies, 61(1), 87-103. https://doi.org/10.1080/10510970903400311

Silberman, M. (1996). Active learning: 101 strategies to teach any subject. Boston: Allyn and Bacon.

Waitkus, J. (2011). Active Learning In Humanities Courses: Helping Students To Think Critically. Journal of College Teaching \& Learning (TLC), 3(10). https://doi.org/10.19030/tlc.v3i10.1671

Wankat, P. (2002). The Effective Efficient Professor: Teaching Scholarship and Service. Boston, MA: Allyn and Bacon. 
Table 1. Effects of active learning on students' material retention

\begin{tabular}{|c|c|c|c|c|c|c|}
\hline Paired T-Tests & $\mathrm{N}$ & $\mathrm{M}$ & $\mathrm{T}$ & $\begin{array}{l}\text { Significance } \\
\text { (2-Tailed) }\end{array}$ & \multicolumn{2}{|c|}{$95 \% \mathrm{CI}$} \\
\hline \multicolumn{7}{|c|}{ Retention between Pre- and Post 1 Surveys } \\
\hline \multicolumn{7}{|l|}{ Control Group } \\
\hline Pre-Survey & 26 & 2.92 & -3.75 & $0.000 * * *$ & -2.09 & -0.61 \\
\hline Post 1 Survey & 26 & 4.27 & & & & \\
\hline \multicolumn{7}{|c|}{ Treatment Group } \\
\hline Pre-Survey & 26 & 3.00 & -6.38 & $0.000 * * *$ & -3.10 & -1.59 \\
\hline Post 1 Survey & 26 & 5.35 & & & & \\
\hline \multicolumn{7}{|c|}{ Retention between Post 1 and Post 2 Surveys } \\
\hline \multicolumn{7}{|l|}{ Control Group } \\
\hline Post 1 Survey & 26 & 4.27 & 0.95 & 0.350 & -0.40 & 1.09 \\
\hline Post 2 Survey & 26 & 3.92 & & & & \\
\hline \multicolumn{7}{|c|}{ Treatment Group } \\
\hline Post 1 Survey & 26 & 5.35 & 0.49 & 0.631 & -0.37 & 0.60 \\
\hline Post 2 Survey & 26 & 5.23 & & & & \\
\hline
\end{tabular}

* Higher scores reflect greater agreement. The surveys each contained 8 questions, providing a range of $0-8$ for each student. 
Figure 1: Concept map developed with treatment group

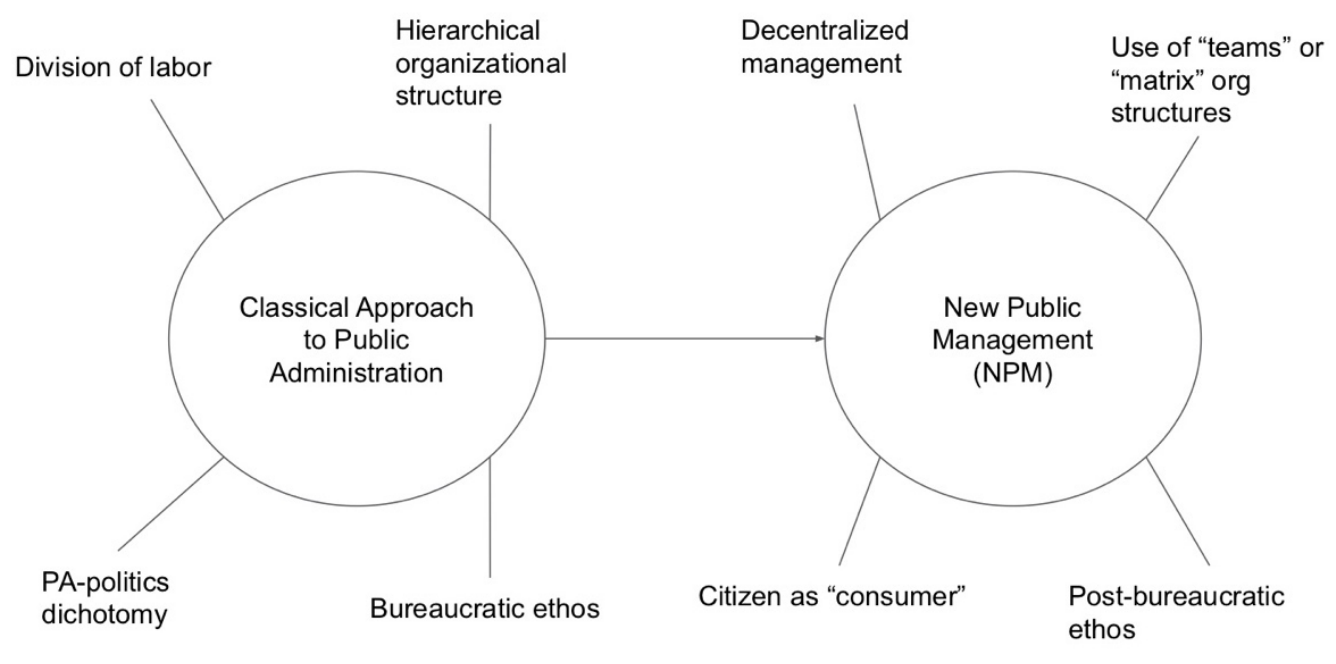


Figure 2: Control group by year in in program.

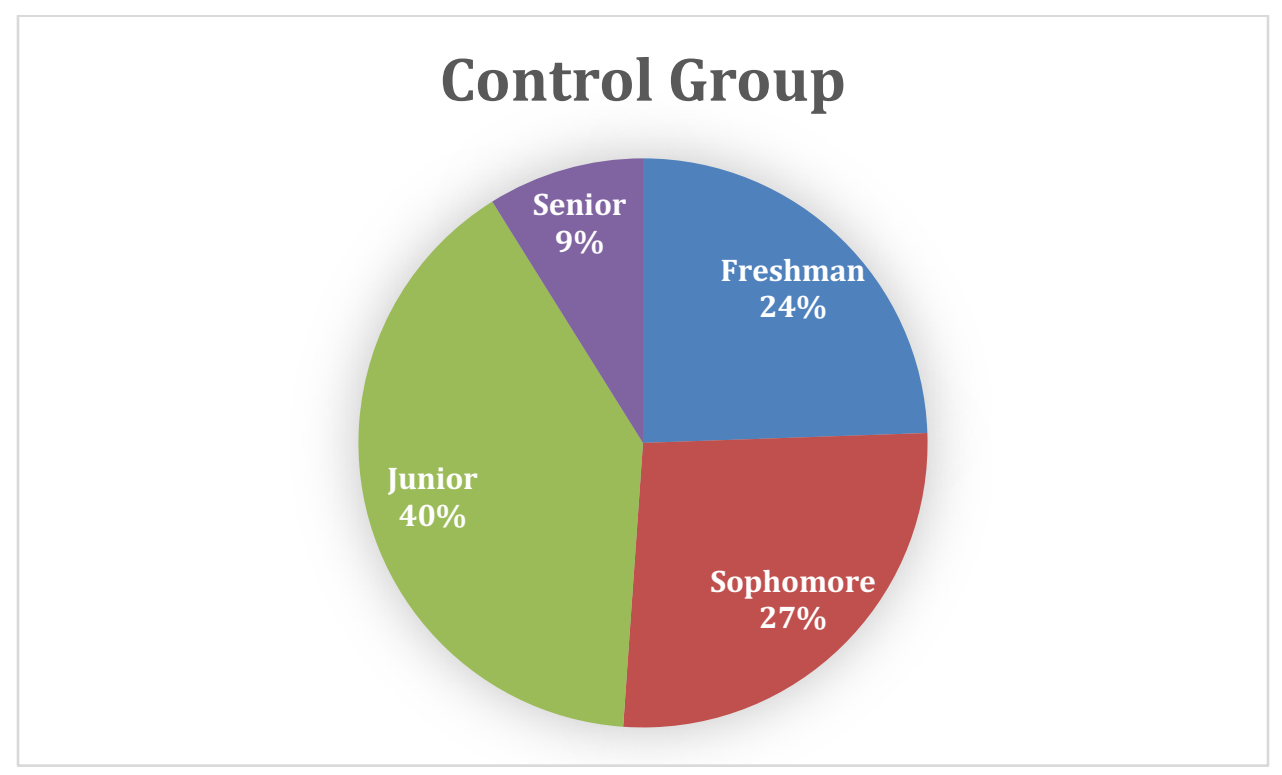


Figure 3: Treatment group by year in program.

\section{Treatment Group}

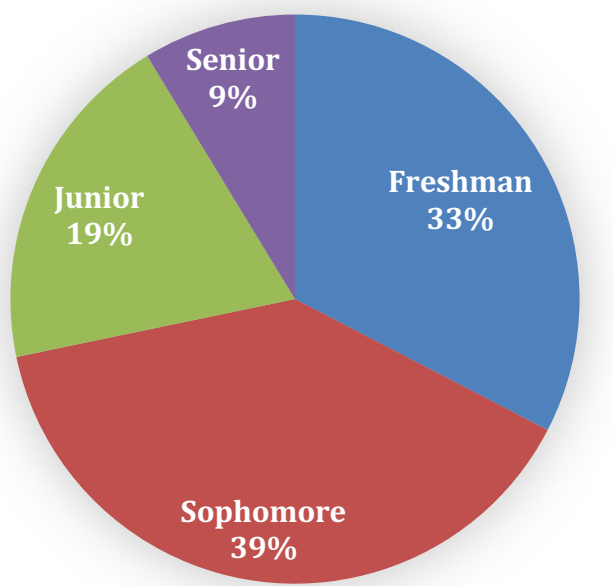


Figure 4. Control Group Box Plots

Retention Score Average by Interval, Control Group

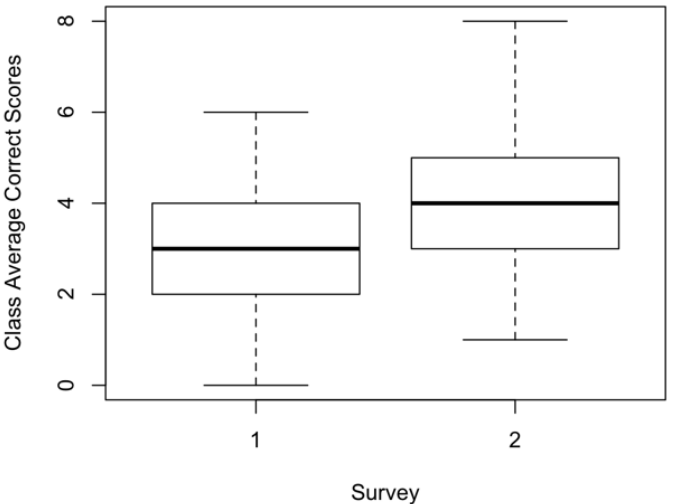

Retention Score Average by Interval, Control Group

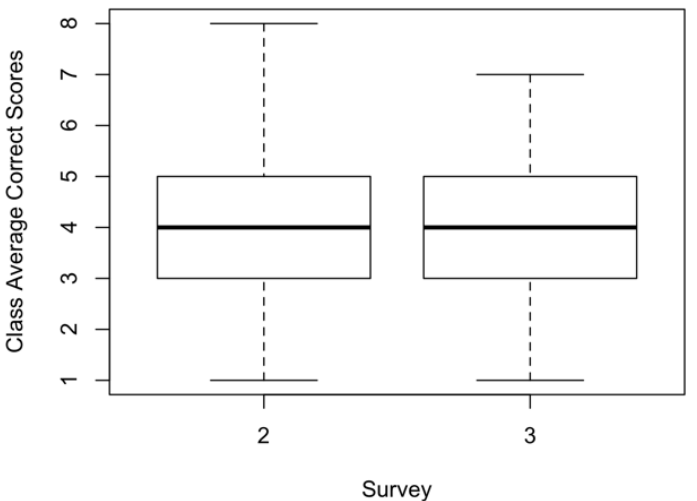


Figure 5. Treatment Group Box Plots

Retention Score Average by Interval, Treatment Group



Retention Score Average by Interval, Treatment Group

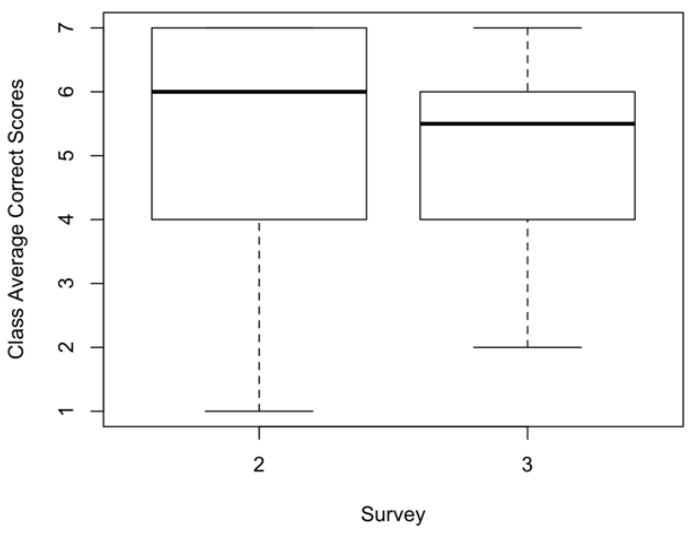

